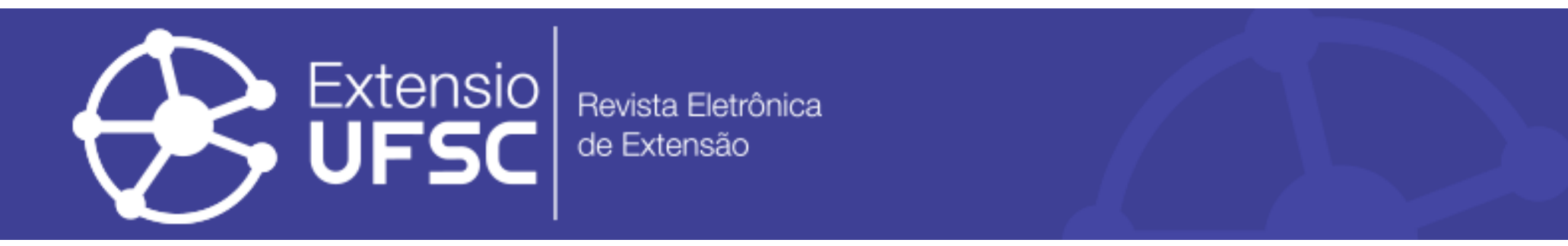

\title{
DIÁLOGOS MUSICAIS: DIFUSÃO RADIOFÔNICA E DEMOCRATIZAÇÃO DA MÚSICA DE CONCERTO
}

\author{
William Teixeira \\ Universidade Federal de Mato Grosso do Sul \\ teixeiradasilva.william@gmail.com \\ Evandro Higa \\ Universidade Federal de Mato Grosso do Sul \\ evandrohiga304@gmail.com
}

\author{
Ana Lúcia Gaborim \\ Universidade Federal de Mato Grosso do Sul \\ anaemarcelo440@gmail.com \\ Jorge Augusto Geraldo \\ Universidade Federal de Mato Grosso do Sul \\ jorgeregencia@gmail.com \\ Pieter Rahmeier \\ Universidade Federal de Mato Grosso do Sul \\ pieter.rahmeier@gmail.com
}

\section{Resumo}

Este artigo objetiva discutir os fundamentos teóricos e as ações concernentes ao projeto de extensão Diálogos musicais, um programa de rádio que promove a democratização do repertório pertencente ao gênero musical conhecido como música de concerto em todas suas vertentes, que atravessam uma tradição secular, mas que hoje encontra pouca disponibilização ao grande público. O programa é veiculado pela Rádio Educativa UFMS em Campo Grande/MS e prevê, junto a tal programação, a inserção de comentários didáticos que orientem a escuta, por parte de professores do curso de música da universidade especializados na temática de cada edição, proporcionando assim um diálogo efetivo com a música, não apenas devido aos enunciados informativos, mas pela relação feita com a realidade social, política e filosófica que envolve cada uma das peças e temáticas propostas.

Palavras-chave: Divulgação Científica. Música de Concerto. Rádio. Democratização.

\section{MUSICAL DIALOGUES: RADIO BROADCASTING AND DEMOCRATIZATION OF CONCERT MUSIC}

\begin{abstract}
Musical Dialogues is a radio program which promotes the democratization of the repertoire belonging to the musical genre known as Concert Music in all its aspects, that cross a secular tradition and, today, it is less available to general public. The program is transmitted by Rádio Educativa UFMS in Campo Grande/MS and provides, along with such musical repertoire, the insertion of didactic comments that guide the listening, by professors of the university's music course, specialized in the theme of each edition, providing, thus, an effective dialogue with music, not only due to the information, but also to the relationship with the social, political and philosophical reality that surrounds each of the pieces and themes proposed.

Keywords: Scientific Dissemination. Concert Music. Radio. Democratization.
\end{abstract}

\section{DIÁLOGOS MUSICALES: DIFUSIÓN RADIOFÓNICA Y DEMOCRATIZACIÓN DE LA MÚSICA DE CONCIERTO}

\section{Resumen}

Diálogos musicales es un programa de radio que promueve la democratización del repertorio perteneciente al género musical conocido como música de concierto en todas sus vertientes, que atravesan una tradición secular, pero que hoy encuentra poca disponibilidad al público en general. El programa es transmitido por Radio Educativa UFMS en Campo Grande / MS y prevé, junto a dicha programación, la inserción de comentarios didácticos que orienten la escucha, por parte de profesores del curso de música de la universidad especializados en la temática de cada edición, proporcionando así un diálogo efectivo con la música, no sólo debido a los enunciados informativos, sino por la relación hecha con la realidad social, política y filosófica que envuelve cada una de las piezas y temáticas propuestas.

Palavras clave: Divulgación Científica. Música de Concierto. Radio. Democratización. 


\section{INTRODUÇÃO}

Embora exerça papel fundamental na constituição da civilização ocidental, a música, sobretudo em sua manifestação própria a ambientes de concerto, tem encontrado resistência para sua veiculação em meios de radiodifusão. Esse instrumento, outrora indissociável da produção musical, tem sido, via de regra, utilizado para fins mais aproximados à indústria cultural do que à promoção da cultura e do estimulo à busca por conhecimento do outro, como veículo para o conhecimento de si próprio e do mundo (ADORNO; HORKHEIMER, 2002: 179). As causas para o afastamento desse vínculo podem ser muitas, mas, como lembra Charles Rosen, a própria luta pela possibilidade da prática livre da música faz parte de sua própria existência enquanto manifestação artística. (ROSEN, 2000: 295).

Dentro disso, vê-se como fundamental a colaboração entre entidades acadêmicas que possam proporcionar não apenas a veiculação de programação musical, mas que viabilizem a própria existência da música enquanto ato humano integral. A série proposta de programas objetiva menos a instrução quanto a um modo de escuta correto do repertório e mais um mecanismo de apropriação, de modo a criar um senso de pertencimento que vá além do cultural, e atinja o caráter humano que a música possui, sendo, assim, um universal que une os indivíduos a despeito de gosto e orientação estética.

Atividades como essas têm sido imprescindíveis em países onde a música de concerto não encontra "ressonância intrínseca" nas culturas locais (KNUSSEN, 2003: 240) e, por essa razão, o projeto de extensão "Diálogos Musicais" toma para si o papel de fomentar atividades que levem a música em sua tradição secular para o maior número de pessoas possível, renovando a crença de que ela é um dos elementos responsáveis por tornar seres humanos verdadeiramente humanos.

Em sua primeira proposta anual, o programa é veiculado semanalmente com uma edição inédita e uma reprise, pela Rádio Educativa UFMS 99,9 FM. A rádio já é uma instituição bastante respeitada em Campo Grande/MS, cidade que guarda um papel importante para o rádio, talvez distintamente de outras capitais do Brasil. Sendo a cidade o berço dos gêneros musicais mais populares, é possível notar-se uma energia musical bastante grande na população do estado, mas que, infelizmente, ainda possui uma baixa oferta de iniciativas educativas no âmbito musical. Embora a região possua uma grande tradição de bandas marciais, devido a sua posição de destaque quanto à situação de importantes bases militares, o ensino de música ainda é eminentemente pragmático, voltado à prática quase que mecanizada em ambientes de igrejas, bases ou a partir dos padrões rítmico-melódicos próprios da música regional. Sendo assim, o programa tem trazido uma proposta nova para o contexto local, no sentido em que difunde 
Diálogos musicais: difusão radiofônica e democratização da música de concerto

muito rapidamente esse repertório pouco conhecido da população, proporcionando um contato com dimensões sócio-políticas da música, que na maior parte das vezes permanece de maneira irrefletida no senso comum. Por essa razão, esta breve reflexão pretende expor as razões e os meios encontrados para suprir tal demanda dentro dos limites de um projeto institucional de extensão.

\section{MATERIAIS E MÉTODOS}

O presente projeto é resultado de um convênio estabelecido entre o Curso de Música da UFMS, a Pró-Reitoria de Extensão, Cultura e Esporte e a Rádio Educativa da mesma instituição. A dinâmica do programa é composta por enunciados explicativos intercalados com a difusão dos fonogramas, como será exemplificado nas transcrições inseridas na seção de discussão.

Uma parte importante da montagem do programa é a busca por priorizar intérpretes e compositores brasileiros nas peças selecionadas para difusão. Essa escolha não tem um propósito ufanista, mas visa reconhecer os músicos de altíssima qualidade que se equiparam ou superam muito do que é mais valorizado no Brasil. A seleção também possibilita minimizar o distanciamento sentido por parte do público quanto ao repertório. Ainda persiste uma sensação de formalização que parece manter a música de concerto em uma redoma afastada da realidade e o programa objetiva realizar o caminho inverso, mostrando como compositores e intérpretes são seres humanos comuns e, como tais, dialogam com as influências sociais que os cercam e com dificuldades que pontualmente a vida lhes apresenta. Os comentários criam, assim, um vínculo de aproximação humana, mais do que ambicionam adestrar a escuta oferecendo qualquer tipo de conhecimento "gnóstico", como se o ouvinte não fosse capaz de entender a música que lhe é apresentada. Pelo contrário, o programa parte da crença de que a música é uma comunicação humana, que se dá de maneira afetiva, não necessitando de qualquer referencialidade denotativa para ser apreendida pelo ouvinte. Infelizmente, muitas políticas de acesso à cultura tendem a menosprezar os espectadores e, com isso, diminuem a própria vitalidade da arte que poderia falar por si mesma e fazer a realização humana que lhe é própria.

O programa é transmitido aos domingos às dezenove horas (horário local) e cada edição inédita tem sua reprise às sextas-feiras, às vinte e duas horas. Além disso, cada edição é disponibilizada para streaming no website da rádio, o que tem sido um importante instrumento de divulgação para outras cidades e estados, onde muitos têm se beneficiado dos aportes didáticos oferecidos. 


\section{RESULTADOS E ANÁLISES}

Os resultados da difusão do programa estão sendo contabilizados de maneira mais rápida do que se imaginou no início da proposta. Um primeiro resultado, que não era esperado, foi a grande adesão de alunos do curso de música, formando eles uma parcela importante dos ouvintes do programa. Enquanto projeto de extensão, esse foi um resultado muito interessante, pois, devido ao tempo reduzido de aula que cada disciplina acaba recebendo diante de uma grade curricular extensa, os próprios alunos puderam se beneficiar das informações disponibilizadas e, principalmente, da escuta do repertório. O ambiente de aula guarda limites que impossibilitam a execução integral de obras musicais importantes e os alunos têm trazido para a sala de aula suas experiências de escuta e suas reflexões acerca das temáticas de cada edição, transformando o programa em um gatilho para discussões que se aprofundam posteriormente em uma dinâmica bastante inesperada e proveitosa. Em geral é notada uma resposta de surpresa, mas muito positiva, a um repertório que poderia chocar a muitos. Essa é uma questão muito interessante, pois, dada a distância que havia da população em relação à música de concerto no geral, o espaço criado não necessita lidar com preconceitos estéticos entre gêneros musicais ou períodos específicos; peças contemporâneas têm sido, por vezes, aquelas que mais boas críticas recebem do público.

\section{MODELOS DE PROGRAMAS}

Abaixo será transcrita uma edição do programa Diálogos Musicais, de modo que possa ser verificada a aplicação do método exposto, bem como a relação entre o repertório e as notas didáticas. O programa em questão possui um enfoque histórico, mas dedicado unicamente a obras escritas por compositoras mulheres, levantando o problema do gênero na historiografia e nas práticas musicais.

\section{Programa \#6 - Compositoras mulheres}

Olá, caro ouvinte da Rádio Educativa UFMS! Eu sou William Teixeira e esse é o programa Diálogos Musicais. Estamos de volta neste programa com mais música de concerto e com algumas breves observações feitas por professores do curso de música da UFMS. Hoje nosso programa tem um tema que, na verdade, gostaríamos que nem precisasse ocupar um programa inteiro, mas ainda é importante que possamos conceder a ele uma atenção especial. 
Vamos ouvir somente peças escritas por compositoras mulheres. Embora isso não pareça nada demais, é raro ouvirmos nomes de mulheres quando começamos a listar os grandes gênios da história da música. Lembramo-nos de Bach, Mozart e Beethoven, mas é difícil lembrarmos de uma mulher em meio a esses nomes. Será que nunca houve nenhuma mulher compositora?

É para responder a essa pergunta que hoje iremos ouvir peças maravilhosas escritas por grandes mulheres do passado e do presente, mas que, por conta de uma historiografia tendenciosa, acabam sempre ficando esquecidas das salas de concerto.

A primeira peça que iremos ouvir é de um dos maiores ícones da música medieval: tratase da compositora, teóloga e, posteriormente, santa, Hildegarda von Bingen. Hildegarda ou Santa Hildegarda, para alguns, foi uma monja beneditina que viveu no século XII e que, dentre suas inúmeras contribuições, deixou cânticos que até hoje são a grande obra-prima da música medieval, dada sua complexidade e beleza em comparação a outras peças do mesmo período. Como se não bastasse Hildegarda ser uma grande compositora, também era uma poetiza fantástica e escrevia as letras das próprias peças, coisa que não era nada comum. Vamos ouvir então, de Hildegarda von Bingen, o cântico "O tu ilustrata", na interpretação do grupo VocaMe:

\section{PEÇA 1: https://www.youtube.com/watch?v=Y HkOSAW73E \\ PEÇA 2: https://www.youtube.com/watch?v=ZX3iW5OUkkg}

Você acabou de ouvir "Lagrime mie", peça da compositora italiana Bárbara Strozzi, em uma interpretação de Marília Vargas, com acompanhamento de Silvana Scarinci e Sérgio Álvarez. Strozzi é tida como uma das maiores revolucionárias dentro do barroco italiano, não só pela musicalidade sem igual, que transformou os tradicionais lamentos, mas por conta de sua luta para poder ser uma compositora. Embora vivesse como uma cortesã em meio aos nobres, era mulher e por isso era alvo de constante abuso, moral e físico. Em meio a uma vida de tanto sofrimento, sua música permanece como um marco de coragem, de uma pessoa que, apesar dos limites impostos, não se cala, expressando sua indignação e inconformidade com os padrões vigentes. Antes de Strozzi, ouvimos "o tu ilustrata" de Hildegarda von Bingen. Voltamos a seguir com mais Diálogos Musicais.

Estamos de volta com o programa Diálogos Musicais e hoje estamos ouvindo composições escritas exclusivamente por mulheres, o que, por mais normal que possa parecer, ainda faz com que muita música de qualidade extrema permaneça distante dos nossos palcos e ouvidos. No bloco anterior ouvimos duas compositoras muito antigas, que foram figuras centrais nas épocas em que viveram. 
Diálogos musicais: difusão radiofônica e democratização da música de concerto

Este também é o caso da próxima compositora que ouviremos. Embora seja mais lembrada por ter sido esposa de Robert Schumann e por ter tido um relacionamento com Johanes Brahms, Clara Wieck Schumann era tida em vida como umas das maiores pianistas do mundo. Entretanto, pouco se conhece a respeito da Clara compositora, que possuía um talento inestimável também nessa área do fazer musical. Infelizmente o machismo de seu tempo mais uma vez agiu para calar sua música e, nesse caso, por meio de seu marido Robert Schumann, que a impeliu a parar de compor, valendo-se de críticas absolutamente destrutivas. Mesmo assim, ainda temos acesso a algumas poucas composições de Clara, que provam sua genialidade e a grande qualidade de sua música. Ouviremos o primeiro movimento, Allegro moderato, de seu trio op. 17, com execução do Trio Kandinsky.

\section{PEÇA 3: https://www.youtube.com/watch?v $={ }_{\mathrm{y} R x a 10 d y C A 8}$ \\ PEÇA 4: https://www.youtube.com/watch?v=PkASGaslaA0}

Acabamos de ouvir o primeiro movimento, Allegro moderato, da Sonata para violoncelo e piano, op. 5 de Ethel Smyth, em performance de Martin Roscoe e Moray Welsh. Outra grande compositora ocultada pela história, Ethel Smyth tem um papel histórico de grande importância, não apenas pela ótima música que fez, mas também porque foi uma das líderes do movimento sufragista na Inglaterra, tendo sido alvo de ataques de todo o tipo por conta de seu ativismo em prol do voto para as mulheres, até então proibido. Em meio a esse contexto de conflito, Ethel Smyth produziu música de alto valor, alinhada com os grandes nomes do romantismo europeu. Antes da sonata, você ouviu o primeiro movimento do trio op. 17 de Clara Schumann, na interpretação do Trio Kandinsky. Voltamos já com o Diálogos Musicais.

Voltamos com o Diálogos Musicais e hoje estamos fazendo nossa habitual jornada pela história da música, mas dessa vez a partir de um ponto de vista feminino, por meio de peças escritas exclusivamente por compositoras mulheres. Neste bloco iremos ouvir um pouco da música que grandes compositoras têm feito hoje e que têm demonstrado sua grande força e contribuição para os rumos atuais de nossa arte. Uma das grandes compositoras brasileiras da nova geração é Michelle Agnes, uma campo-grandense que reside em Paris há vários anos e que tem desenvolvido uma carreira internacional de muito sucesso, tendo recebido diversos prêmios, além de ter concluído seu doutorado na USP. Hoje Michelle trabalha no IRCAM, que é o maior centro de pesquisa e produção de música contemporânea do mundo. De Michelle, vamos ouvir a peça Play and Theory of the Duende, escrita ano passado sobre poemas de Garcia Lorca e tocada nesta gravação pelo Ensemble Multilaterale. 
Diálogos musicais: difusão radiofônica e democratização da música de concerto

PEÇA 5: https://soundcloud.com/michelle-agnes/play-and-theory-of-the-duende-forbass-flute-violin-cello-and-harp-2016

PEÇA 6: https://soundcloud.com/valeriabonafe/a-menina-que-virou-chuva-2013-fororchestra

Você acabou de ouvir "A menina que virou chuva", da compositora paulistana Valéria Bonafé, em gravação da Orquestra Sinfônica do Paraná. Valéria, assim como a campo-grandense Michelle, que ouvimos antes, é uma das grandes compositoras de sua geração, tendo concluído seu doutorado também na USP. Hoje é uma das principais ativistas pela valorização da mulher dentro da música de concerto e é professora de composição musical na Escola de Música do Estado de São Paulo.

Esse foi mais um Diálogos Musicais. Voltamos semana que vem com mais música e informação.

\section{CONSIDERAÇÕES FINAIS}

O projeto obteve sucesso em sua avaliação institucional, de maneira que será continuado em 2018. Além disso, destaca-se como evidência do efeito positivo deste programa seu impacto nacional junto à comunidade acadêmica, que fez com que fosse convidado a transmitir as edições brasileiras do projeto Weaving Music for Radio by Latin American Women Composers, promovido pela UNESCO e que será veiculado durante os meses de abril e maio na Rádio Educativa UFMS.

Fruto direto do programa acima transcrito acerca de compositoras mulheres, o projeto da UNESCO consiste justamente na encomenda de novas peças escritas por compositoras para o rádio. Essa se torna uma consideração importante pois demonstra o impacto da música dentro da questão do gênero e como as estruturas institucionais podem ser instrumentalizadas para promover a igualdade em contextos pouco abordados sob tal problemática.

Por fim, destaca-se o importante papel dos discentes na elaboração de algumas das edições do programa, o que deve ser ampliado na próxima temporada, de maneira a possibilitar uma experiência extensionista mais eficiente e também como incentivo para a realização de pesquisas de conteúdo que extrapolem o contexto de sala de aula, atingindo assim um impacto social de fundamental importância. 
Diálogos musicais: difusão radiofônica e democratização da música de concerto

\section{REFERÊNCIAS}

ADORNO, Theodor; HORKHEIMER, Max. A indústria cultural: o iluminismo como mistificação de massas. Pp. 169 a 214. In: LIMA, Luiz Costa. Teoria da cultura de massa. São Paulo: Paz e Terra, 2002.

HARNONCOURT. Nikolaus. O diálogo musical: Monterverdi, Bach e Mozart. Tradução de Luiz Paulo Sampaio. Rio de Janeiro: Zahar, 1993.

KNUSSEN, Sue. Educational Programs. In: LAWSON, Colin (Ed.). The Cambridge Companion to the Orchestra. Cambridge: Cambridge University Press, 2003.

ROSEN, Charles. Critical Entertainments: Music Old and New. Cambridge: Harvard University Press, 2000

Recebido em: 06/10/2017

Aceito em: 25/04/2018 